\title{
Short- and long-term outcomes of LigaSure versus conventional surgery for curative gastric cancer resection: a matched pair analysis
}

\author{
Haiyang Zhou $\cdot$ Wei Yi $\cdot$ Jian Zhang $\cdot$ \\ Weijun Wang $\cdot$ Yi Wang • Wenchao Gao • \\ Zhiqian Hu
}

Received: 13 March 2014/ Accepted: 28 July 2014/Published online: 17 August 2014

(c) The International Gastric Cancer Association and The Japanese Gastric Cancer Association 2014

\begin{abstract}
Background The LigaSure vessel sealing system allows dissection and hemostasis in a safe and quick way, and it has been reported to be an effective tool to shorten operative time and reduce intraoperative blood loss for various surgeries. However, short- and long-term outcomes in comparison with conventional surgery for gastric cancer resection are limited.

Methods Between January 2005 and December 2009, 121 patients underwent curative resection for gastric cancer with LigaSure. Perioperative and long-term results were compared with those of 242 matched patients who received curative resection for gastric cancer with the conventional technique. Immediate operation outcomes, operation morbidity, recurrence and survival were compared between groups.

Results In the LigaSure group compared with the conventional group, operation time was 156 versus $183 \mathrm{~min}$ $(P<0.0001)$, intraoperative blood loss was 181 versus $236 \mathrm{ml}(P=0.042)$, intraoperative blood transfusion was 68 versus $161 \mathrm{ml}(P=0.014)$, and hospital stay was 11.9 versus 13.6 days $(P=0.001)$. There were no differences in operation morbidity, recurrence rates, overall and diseasefree survival between the LigaSure and conventional groups.

Conclusions LigaSure is associated with shorter operation time and hospital stay, less blood loss and transfusion, and comparable operation morbidity and long-term
\end{abstract}

H. Zhou · W. Yi · J. Zhang · W. Wang · Y. Wang · W. Gao · Z. Hu $(\square)$

Department of General Surgery, Changzheng Hospital, Second Military Medical University, No. 415, Fengyang Road,

Shanghai 200003, People's Republic of China

e-mail: czhuzq@aliyun.com outcomes in comparison with conventional surgery for curative gastric cancer resection.

Keywords Gastric cancer - LigaSure - Operation time · Blood loss $\cdot$ Long-term outcomes

\section{Introduction}

Gastric cancer is still one of the most common cancers worldwide [1]. Currently, gastrectomy with lymph node (LN) dissection remains the mainstay of curative treatment [2]. The operation involves extensive dissection and requires careful hemostasis with a clear operative field for high-quality LN dissection and to avoid any accidental injury. The conventional resection technique during gastrectomy is performed with scissors or electrocautery for dissection, and ligatures or sutures for hemostasis. As a result, it is often associated with a long surgical time and significant bleeding [3]. In recent years, a new hemostatic tool, namely the LigaSure vessel sealing system, has been developed. It provides a new alternative for dissection and hemostasis with one instrument, which relies on the principle of bipolar electrocoagulation, and seals blood vessels up to $7 \mathrm{~mm}$ in diameter [4]. It has been described with increasing frequency in various procedures (thyroid [5], esophageal [6], lung [7], hepatobiliary [8], gynecological [9], breast [10], etc.), and the technology holds the promise of reducing surgical time and intraoperative blood loss. Although a preliminary study with a small sample size indicated using LigaSure was associated with shorter operative time and decreased blood loss compared with the conventional method in extended gastric cancer resection [11], long-term outcomes regarding tumor recurrence and patient survival remain unclear. To support its expansion 
toward being an effective tool for surgical treatment of gastric cancer, research on its long-term results such as survival is clearly warranted. In this study, we compared the short- and long-term outcome of LigaSure versus conventional surgery for curative gastric cancer resection.

\section{Patients and methods}

Patient selection

This is a retrospectively designed study, with prospective collection of patients' data in a computerized database recording all the preoperative, peri- and postoperative information. From January 2005 to December 2009, 942 patients with gastric cancer received a curative resection at our center; 121 patients who underwent curative gastric cancer resection with LigaSure were included in the study. For comparison, 242 patients who underwent curative gastric cancer resection with the conventional technique in the same period were matched for type of resection, histopathology, age and gender. To evaluate whether the perioperative course and postoperative parameters, including long-term survival, were different for LigaSure and conventional surgery, a matched-pairs analysis was performed.

\section{Surgical technique}

All gastric cancer resections were performed by the same team of experienced surgeons. Total or subtotal (proximal or distal) gastrectomy was performed depending on the location of the tumor in the stomach. Gastroduodenostomy (Billroth I) or gastrojejunostomy (Billroth II) in subtotal gastrectomy and Roux-en-Y esophagojejunostomy in total gastrectomy were the standard surgical procedures used according to our institute's policy. LN dissection was performed according to the Japanese gastric cancer treatment guideline [12].

In the LigaSure group, preparation, dissection and hemostasis of all vessels, as well as lymphatic ducts, were performed with the LigaSure Atlas device (Valleylab, Boulder, CO, USA). For each major vessel, such as the left gastric artery, the LigaSure device was applied twice and the vessel then transected between closures. In the conventional technique group, vessels and lymphatic ducts were ligated with or without sutures.

After the operation, one or two rubber drains were placed near the subhepatic and anastomotic sites. All other aspects of patient care followed our in-house-established protocol.
Table 1 Matched pair analysis of LigaSure and conventional gastric cancer resections: clinical characteristics

\begin{tabular}{|c|c|c|c|}
\hline & $\begin{array}{l}\text { LigaSure group } \\
(n=121)\end{array}$ & $\begin{array}{l}\text { Conventional group } \\
(n=242)\end{array}$ & $P$ \\
\hline Age (years) & $58.0(23-81)$ & $58.7(31-86)$ & 0.395 \\
\hline Gender (M:F) & $73: 48$ & $152: 90$ & 0.648 \\
\hline $\begin{array}{l}\text { Body mass } \\
\text { index }\end{array}$ & $22.0(16.8-33.4)$ & $22.3(15.4-37.5)$ & 0.399 \\
\hline $\begin{array}{l}\text { Hemoglobin } \\
(\mathrm{g} / \mathrm{dl})\end{array}$ & $12.3(5.3-16.2)$ & $12.5(5.2-16.7)$ & 0.146 \\
\hline $\begin{array}{l}\text { Preoperative } \\
\text { anemia }\end{array}$ & $42(34.7 \%)$ & $86(35.5 \%)$ & 0.908 \\
\hline Albumin (g/l) & $40.4(27-51)$ & $40.5(28-55)$ & 0.664 \\
\hline \multicolumn{4}{|c|}{ Type of resection } \\
\hline $\begin{array}{l}\text { Distal } \\
\text { gastrectomy }\end{array}$ & $83(68.6 \%)$ & $166(68.6 \%)$ & 0.999 \\
\hline $\begin{array}{l}\text { Proximal } \\
\text { gastrectomy }\end{array}$ & $12(10.0 \%)$ & $24(10.0 \%)$ & 0.999 \\
\hline $\begin{array}{l}\text { Total } \\
\text { gastrectomy }\end{array}$ & $26(21.4 \%)$ & $52(21.4 \%)$ & 0.999 \\
\hline $\begin{array}{l}\text { Other organ } \\
\text { resection }\end{array}$ & $9(7.4 \%)$ & $18(7.4 \%)$ & 0.999 \\
\hline Tumor size & $4.1(0.5-12)$ & $3.9(0.3-15)$ & 0.119 \\
\hline \multicolumn{4}{|c|}{ Tumor differentiation } \\
\hline Poor & $68(56.2 \%)$ & $136(56.2 \%)$ & 0.999 \\
\hline Moderate & $47(38.8 \%)$ & $95(39.2 \%)$ & 0.999 \\
\hline Well & $6(4.9 \%)$ & $11(4.6 \%)$ & 0.999 \\
\hline \multicolumn{4}{|l|}{ TNM stage } \\
\hline I & $37(30.6 \%)$ & $79(32.6 \%)$ & 0.722 \\
\hline II & $35(28.9 \%)$ & $77(31.8 \%)$ & 0.630 \\
\hline III & $49(40.5 \%)$ & $86(35.5 \%)$ & 0.340 \\
\hline
\end{tabular}

Values are expressed as mean (range)/(percentage)

\section{Short-term outcomes}

Preoperative demographic data, details of the surgical procedures and all relevant perioperative variables, including the postoperative course and complications, and histopathological outcomes were recorded in a prospectively maintained database.

Long-term outcomes

For the assessment of long-term outcomes, data regarding tumor recurrence and patient survival from our prospectively maintained database were used. The patients were followed up until death or until the date of last follow-up of 1 July 2013. Tumor stage was classified according to the 7th edition of the International Union Against Cancer/ American Joint Committee on Cancer guidelines [13]. 
Table 2 Matched pair analysis of LigaSure and conventional gastric cancer resections: operation details and short-term outcomes

\begin{tabular}{|c|c|c|c|}
\hline & $\begin{array}{l}\text { LigaSure } \\
\text { group } \\
(n=121)\end{array}$ & $\begin{array}{l}\text { Conventional } \\
\text { group } \\
(n=242)\end{array}$ & $P$ \\
\hline $\begin{array}{l}\text { Duration of operation } \\
\text { (min) }\end{array}$ & $156(60-360)$ & $183(90-440)$ & $<0.0001$ \\
\hline $\begin{array}{l}\text { Intraoperative blood loss } \\
(\mathrm{ml})\end{array}$ & $181(50-2000)$ & $236(50-2000)$ & 0.042 \\
\hline $\begin{array}{l}\text { Patients with massive } \\
\text { blood loss }\end{array}$ & $8(6.6 \%)$ & $53(21.9 \%)$ & 0.0002 \\
\hline $\begin{array}{l}\text { Intraoperative blood } \\
\text { transfusion }(\mathrm{ml})\end{array}$ & $68(0-1200)$ & $161(0-2200)$ & 0.014 \\
\hline $\begin{array}{l}\text { Patients received blood } \\
\text { transfusion }\end{array}$ & $12(9.9 \%)$ & $68(28.1 \%)$ & $<0.0001$ \\
\hline Splenectomy & $3(2.5 \%)$ & $13(5.4 \%)$ & 0.281 \\
\hline Patients with complication & $11(9.1 \%)$ & $24(9.9 \%)$ & 0.999 \\
\hline Leakage & $3(2.5 \%)$ & $6(2.5 \%)$ & 0.999 \\
\hline Bleeding & $0(0 \%)$ & $3(1.2 \%)$ & 0.668 \\
\hline Pancreatic fistula & $1(0.8 \%)$ & $1(0.4 \%)$ & 0.999 \\
\hline Intraabdominal abscess & $1(0.8 \%)$ & $2(0.8 \%)$ & 0.999 \\
\hline Wound infection & $4(3.3 \%)$ & $9(3.7 \%)$ & 0.999 \\
\hline Delayed gastric emptying & $1(0.8 \%)$ & $1(0.4 \%)$ & 0.999 \\
\hline Pneumonia & $1(0.8 \%)$ & $5(2.1 \%)$ & 0.668 \\
\hline Number of LNs dissected & $25.9(8-34)$ & $26.7(8-37)$ & 0.949 \\
\hline Number of metastatic LNs & $3.4(0-19)$ & $3.3(0-31)$ & 0.867 \\
\hline Reoperation & $1(0.8 \%)$ & $2(0.8 \%)$ & 0.999 \\
\hline Perioperative mortality & $1(0.8 \%)$ & $2(0.8 \%)$ & 0.999 \\
\hline Hospital stay (days) & $11.9(8-24)$ & $13.6(5-39)$ & 0.001 \\
\hline
\end{tabular}

Values are expressed as mean (range)/(percentage)

Statistical analysis

The baseline characteristics of patients were expressed as mean with range. The paired $t$ test was used to compare continuous variables, and the Fisher's exact test was used to compare categorical variables. Survival analysis was performed using the time of overall survival or disease-free survival. Survival curves were computed using the KaplanMeier method and compared between groups by the logrank test. Significance was defined as $P<0.05$. All statistical calculations were made with the SPSS software (SPSS, Chicago, IL, USA).

\section{Results}

The two groups of patients had a similar body mass index, preoperative hemoglobin level and albumin. The tumor size, differentiation and stage were also comparable (Table 1).

Table 2 summarizes the operation details and short-term outcomes. The mean operation time in the LigaSure group was significantly shorter than that in the conventional group (mean 156 vs. 183 min, $P<0.0001$ ). Blood loss was significantly lower in the LigaSure group than in the conventional group (mean 181 vs. $236 \mathrm{ml}, P=0.042$ ). Eight $(6.6 \%)$ patients in the LigaSure group had massive intraoperative blood loss $(\geq 400 \mathrm{ml})$ compared with $53(21.9 \%)$ patients in the conventional group $(P=0.0002)$. The volume of intraoperative blood transfusion was also significantly lower in the LigaSure group than in the conventional group (mean 68 vs. $161 \mathrm{ml}, P=0.014$ ). More patients received blood transfusions in the conventional group than in the LigaSure group (9.9 vs. $28.1 \%$, $P<0.0001)$. Postoperative complication and reoperation rates were comparable between groups. Numbers of LNs dissected and metastatic LNs were also similar between groups. There was one perioperative death (death within 30 days of surgery) in the LigaSure group and two in the conventional group. The mean hospital stay was 11.9 days in the LigaSure group and that of the conventional group was 13.6 days $(P=0.001)$.

In the LigaSure group, the 1-year survival was $95.9 \%$, 3-year survival was $75.2 \%$, and 5-year survival was $59.0 \%$. In the conventional group, the 1-year survival was $92.1 \%$, 3-year survival was $73.6 \%$, and 5-year survival was $60.6 \%(P=0.949)$ (Fig. 1a). Patients with early (stage I) gastric cancer in the LigaSure group had a 1-year survival of $97.3 \%$, 3-year survival of $94.6 \%$ and 5-year survival of $92.3 \%$ after the operation. Their counterparts in the conventional group had 1-year survival of $97.5 \%$, 3-year survival of $94.9 \%$ and 5-year survival of $87.9 \%$ $(P=0.711)$ (Fig. 1b). Patients with advanced (stage II and III) gastric cancer in the LigaSure group had 1-year survival of $95.2 \%$, 3-year survival of $66.7 \%$ and 5-year survival of $43.9 \%$. Their counterparts in the conventional group had corresponding rates at 89.6, 63.2 and $47.0 \%$ $(P=0.890)$ (Fig. 1c). In the LigaSure group, the 1-year disease-free survival was $90.1 \%, 3$-year disease-free survival was $73.6 \%$, and 5-year disease-free survival was $57.8 \%$. The conventional group had corresponding rates at $86.4,71.5$ and $59.4 \%(P=0.997)$ (Fig. 2a). In the LigaSure group, patients with early (stage I) gastric cancer had 1-year disease-free survival of $97.3 \%, 3$-year disease-free survival of $94.6 \%$ and 5-year disease-free survival of $92.3 \%$. The corresponding rates in the conventional group were 97.5, 92.4 and $87.9 \%(P=0.727)$ (Fig. 2b). In the LigaSure group, patients with advanced (stage II and III) gastric cancer had 1-year disease-free survival of $86.9 \%$, 3 -year disease-free survival of $64.3 \%$ and 5-year diseasefree survival of $42.1 \%$. The corresponding rates in the conventional group were 81.0, 61.3 and $45.3 \%$ $(P=0.955)$ (Fig. 2c).

The mortality was comparable between the LigaSure and conventional group. There were no differences in 
Fig. 1 a Overall survival of all patients with gastric cancer. b Overall survival of patients with early (stage I) gastric cancer. c Overall survival of patients with advanced (stage II and stage III) gastric cancer
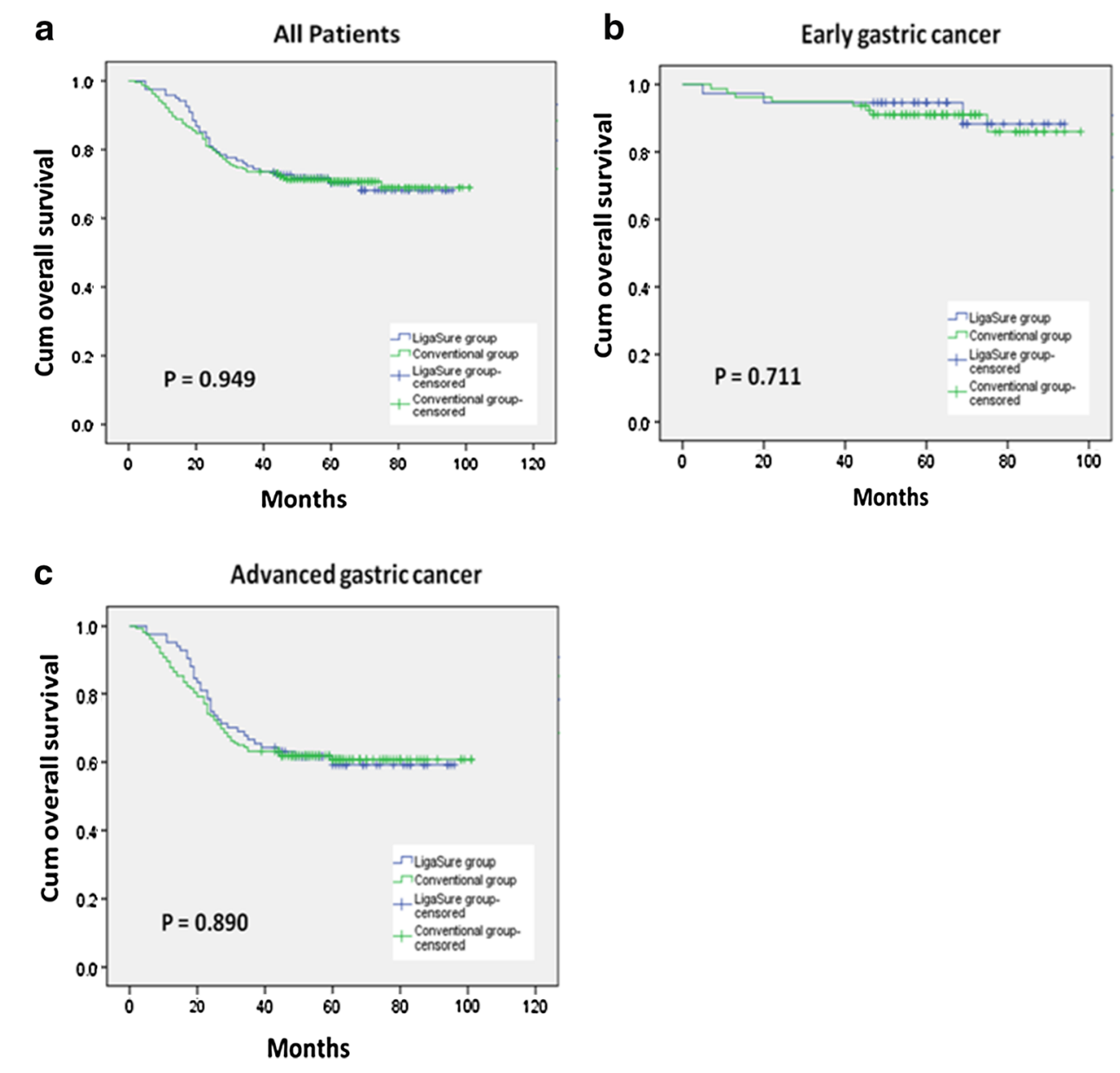

operative, cancer-related and other mortality between the two groups. In addition, no differences in local/peritoneal or distant recurrence were noted between the LigaSure and conventional groups (Table 3). In addition, total costs related to the surgery were comparable between the two groups (mean, LigaSure: US\$ 4367 vs. conventional: US\$ 4292, $P=0.923)$

\section{Discussion}

Extended lymphadenectomy or D2 dissection has been advocated for curative treatment of gastric cancer. Although laparoscopy or robotic surgeries for gastric cancer have been extensively explored in recent years [14-16], our department prefers the open approach for curative gastric cancer resection. Thus, all the cases included in this study were performed by the open technique. Nevertheless, no matter whether it is performed by an open or laparoscopic approach, extended gastric cancer resection requires exhaustive hemostasis with a dry operative field for highquality $\mathrm{LN}$ dissection and to avoid inadvertent damage to adjacent structures. However, the conventional procedure is known to have a long operation time and significant blood loss. Thanks to the developments in technology, electrosurgical instruments have become increasingly sophisticated. One representative product, LigaSure, which utilizes high-current, low-voltage radiofrequency energy, in combination with a feed-back-controlled response system that automatically delivers and disrupts power according to the composition and impedance of the tissue, was developed as a useful alternative to the traditional devices and methods used for ligating vessels and tissue bundles. Although several investigators have described the use of LigaSure in different procedures, short- and longterm outcomes in comparison with conventional surgery for gastric cancer resection are limited.

According to our results, use of LigaSure in curative gastric cancer surgery shortened the operation time by $27 \mathrm{~min}$ and reduced the intraoperative blood loss by $55 \mathrm{ml}$ compared with conventional surgery. There were no differences in complication rates. These data corroborated results of the previous small trial [11]. By shortening the general anesthesia time and reducing blood loss, the LigaSure also accelerated postoperative recovery and shortened the hospital stay by approximately 2 days. 
Fig. 2 a Disease-free survival of all patients with gastric cancer. b Disease-free survival of patients with early (stage I) gastric cancer. c Disease-free survival of patients with advanced (stage II and stage III) gastric cancer a

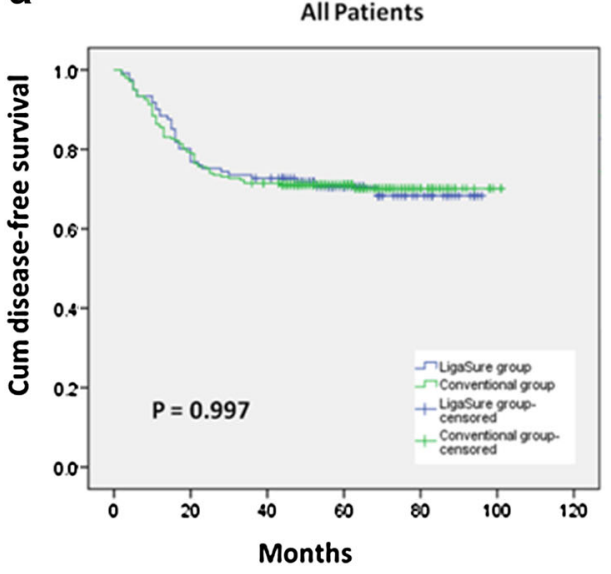

b Early gastric cancer

C

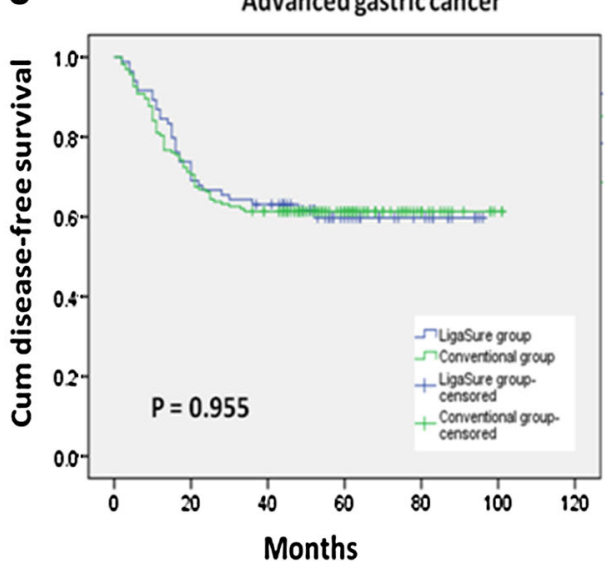

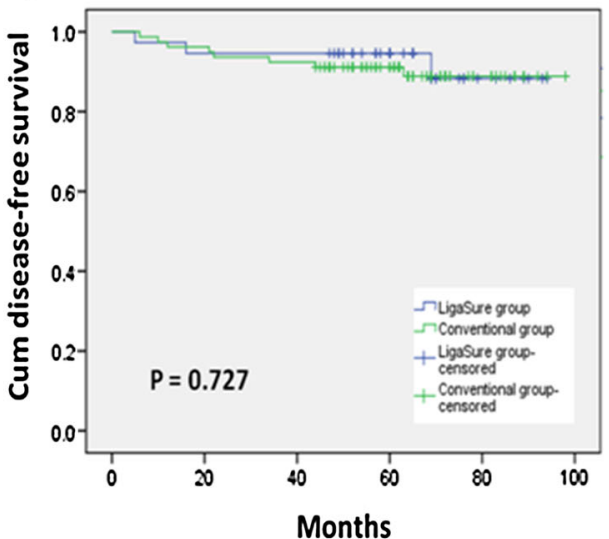

Months
Table 3 Matched pair analysis of LigaSure and conventional gastric cancer resections: mortality and recurrence

\begin{tabular}{lccc}
\hline & $\begin{array}{l}\text { LigaSure } \\
\text { group }(n=121)\end{array}$ & $\begin{array}{l}\text { Conventional } \\
\text { group }(n=242)\end{array}$ & $P$ \\
\hline Mortality & $36(29.8 \%)$ & $71(29.3 \%)$ & 0.999 \\
Operative & $1(0.8 \%)$ & $2(0.8 \%)$ & 0.999 \\
Cancer-related & $34(28.1 \%)$ & $63(26.0 \%)$ & 0.707 \\
Others & $2(1.2 \%)$ & $6(2.5 \%)$ & 0.724 \\
Recurrence & $36(29.8 \%)$ & $67(27.7 \%)$ & 0.712 \\
Local/peritoneal & $29(24.0 \%)$ & $53(21.9 \%)$ & 0.690 \\
Distant & $10(8.3 \%)$ & $19(7.8 \%)$ & 0.999 \\
\hline
\end{tabular}

Values are expressed as mean (range)/(percentage)

The benefits of shortening the operation time and reducing blood loss may be attributed to several advantages of LigaSure, which possibly simplify resection during gastric cancer surgery. First, it is able to seal vessels up to $7 \mathrm{~mm}$ in $2-7 \mathrm{~s}$ so that hundreds of manual ties or sutures can be avoided, which can reduce the intraoperative configuration and change of equipment, and possibly shorten the operating time. It simultaneously closes both sides of the target vessels, thereby decreasing bleeding from the resected side. In addition, fast sealing without foreign bodies such as nonabsorbable threads may reduce the risk of surgical site infection [17]. Second, it saves time and makes it easier to perform a ligature with difficult vascular pedicles or when there is a difficulty in creating a space (such as short gastric vessels). In our experience, injury to the spleen occurs most frequently when dividing the short gastric vessels, which may lead to massive hemorrhage, even bringing about unnecessary spleen resection. The long hand piece of LigaSure allows easy placement in a narrow view and effectively seals the vessels, especially in obese patients and those with a narrow substernal angle [6]. In fact, although without statistical significance, our results showed the incidence of additional splenectomy was higher in the conventional group than in the LigaSure group (5.4 vs. $2.5 \%$ ). Third, the LigaSure technique is operator independent, whereas the hemostasis achieved by conventional sutures and ligation is skill and operator dependent. It is easy to use and does not require a learning curve or expert surgical skill. Once it has been prepared, it takes effect without any further action on the part of the surgeon. 
This ergonomically efficient and easy-to-use instrument may help to reduce the stress of surgeons and shorten the learning curve of complex surgery for young surgeons.

The results also demonstrated that LigaSure was safe for use in curative gastric cancer surgery. No complications related to the use of the LigaSure were encountered. No resuturing in areas cut and sealed using the LigaSure was required in any of our cases. In addition, no late bleeding was observed in the LigaSure group during follow-up. In fact, vessels sealed with LigaSure were shown to withstand well above three times the physiological systolic blood pressure without bursting [4]. There were no necrotic tissues or thrombi proximal to the sealed end; thus, there was no chance of the sealed stump reopening [18]. On contrast, three postoperative bleedings were encountered in the conventional group, possibly because of knot slipping, although all three cases were treated successfully by conservative management.

Another concern regarding the use of LigaSure is the adequacy of LN retrieval, which is significantly associated with local recurrence and long-term survival. The optimal gastric cancer management recommendation by an international RAND/UCLA expert panel requires assessment of 16 or more LNs [19], whereas a multicentric Western analysis suggested retrieval of more than 25 LNs [20]. The present study showed the mean numbers of LNs examined were more than 25 in both groups, and there were no significant differences between groups. Because of the limited thermal alteration $(<1.5 \mathrm{~mm}$ beyond the tissue within the jaws), surgeons can use LigaSure to dissect LNs closed to the blood vessels, leading to complete removal of the target LNs, with minimal risk of damage to delicate adjacent structures [21]. Also, better hemostasis provides better vision of the surgical area and improves the LN clearance.

Although LigaSure has been widely accepted and adopted in gastrointestinal surgery, to date, long-term survival analysis is lacking, especially in comparison to conventional surgery. To our knowledge, this study is the first report to comment on the long-term outcome of patients with gastric cancer receiving LigaSure surgery. There were no differences in recurrence rates, overall and disease-free survival between LigaSure and conventional groups. The recurrence pattern was similar to that found in the previous study [22]. In reference to the stage of disease, no survival differences were found between the two approaches in both early and advanced gastric cancer patients.

One certain disadvantage of the use of LigaSure is the high cost of each disposable hand piece. However, the potential added cost should be compared with the benefit in operation time savings and in the reduction of transfusion requirements and hospital stays. As total costs related to the surgery were comparable between the two groups in this study, we believe that the reduction in blood transfusion cost and the anesthesia fee as well as the reduction in hospital stay may compensate for the cost of LigaSure. In addition, the increased comfort of surgeons should also be emphasized. The benefits may render this device costeffective. Besides the high cost of the LigaSure, education on surgical techniques for young surgeons is another disadvantage. The limited use of ligation reduces the practice opportunities of young surgeons who work as assistants. They may lose a chance to learn surgical techniques under open laparotomy. In the future, we will need to develop efficient learning strategies to help young surgeons master the traditional surgical techniques.

In conclusion, our study showed the use of LigaSure is associated with shorter operation time and hospital stay, less intraoperative blood loss and transfusion, and comparable operation morbidity and long-term outcomes in comparison with conventional surgery for curative gastric cancer resection. Thus, LigaSure offers a rapid, reliable and easily adapted method for gastric cancer resection that we believe advances the field.

Acknowledgments This work was supported by the National Natural Science Foundation of China (grant no. 31100681), Shanghai Natural Science Foundation (grant no. 11ZR1449000), Shanghai Rising Star Foundation (grant no. 11CG42), Shanghai Basic Research Program (no. 12JC1411402) and Shanghai nanotechnology program (no. $11 \mathrm{~nm} 0504800)$.

Conflict of interest The authors declare that there are no conflicts of interest.

\section{References}

1. Jemal A, Bray F, Center MM, et al. Global cancer statistics. CA Cancer J Clin. 2011;61:69-90.

2. Songun I, Putter H, Kranenbarg EM, et al. Surgical treatment of gastric cancer: 15-year follow-up results of the randomised nationwide Dutch D1D2 trial. Lancet Oncol. 2010;11:439-49.

3. Sano T, Sasako M, Yamamoto S, et al. Gastric cancer surgery: morbidity and mortality results from a prospective randomized controlled trial comparing D2 and extended para-aortic lymphadenectomy-Japan Clinical Oncology Group study 9501. J Clin Oncol. 2004;22:2767-73.

4. Kennedy JS, Stranahan PL, Taylor KD, et al. High-burst-strength, feedback-controlled bipolar vessel sealing. Surg Endosc. 1998;12:876-8.

5. Singh P, O'Connell D, Langille M, et al. LigaSure versus conventional hemostasis in thyroid surgery: prospective randomized controlled trial. J Otolaryngol Head Neck Surg. 2010;39:378-84.

6. Eroglu A, Turkyilmaz A, Aydin Y, et al. The use of the LigaSure vessel sealing system in esophageal cancer surgery. Ann Thorac Surg. 2007;84:2076-9.

7. Tsunezuka Y, Waseda R, Yachi T. Electrothermal bipolar vessel sealing device LigaSure for pulmonary artery ligation-burst pressure and clinical experiences in complete video-assisted thoracoscopic major lung resection for lung cancer. Interact Cardiovasc Thorac Surg. 2010;11:229-33. 
8. Ikeda M, Hasegawa K, Sano K, et al. The vessel sealing system (LigaSure) in hepatic resection: a randomized controlled trial. Ann Surg. 2009;250:199-203.

9. Bansal N, Roberts WS, Apte SM, et al. Electrothermal bipolar coagulation decreases the rate of red blood cell transfusions for pelvic exenterations. J Surg Oncol. 2009;100:511-4.

10. Manouras A, Markogiannakis H, Genetzakis M, et al. Modified radical mastectomy with axillary dissection using the electrothermal bipolar vessel sealing system. Arch Surg. 2008;143:575-81.

11. Lee WJ, Chen TC, Lai IR, et al. Randomized clinical trial of Ligasure versus conventional surgery for extended gastric cancer resection. Br J Surg. 2003;90:1493-6.

12. Association Japanese Gastric Cancer. Japanese gastric cancer treatment guidelines 2010 (ver. 3). Gastric Cancer. 2011;14:113-23.

13. Edge SB, Compton CC. The American Joint Committee on Cancer: the 7th edition of the AJCC cancer staging manual and the future of TNM. Ann Surg Oncol. 2010;17:1471-4.

14. Kim YW, Baik YH, Yun YH, et al. Improved quality of life outcomes after laparoscopy-assisted distal gastrectomy for early gastric cancer: results of a prospective randomized clinical trial. Ann Surg. 2008;248:721-7.

15. Viñuela EF, Gonen M, Brennan MF, et al. Laparoscopic versus open distal gastrectomy for gastric cancer: a meta-analysis of randomized controlled trials and high-quality nonrandomized studies. Ann Surg. 2012;255:446-56.

16. Song J, Oh SJ, Kang WH, et al. Robot-assisted gastrectomy with lymph node dissection for gastric cancer: lessons learned from an initial 100 consecutive procedures. Ann Surg. 2009;249:927-32.

17. Faraday N, Rock P, Lin EE, et al. Past history of skin infection and risk of surgical site infection after elective surgery. Ann Surg. 2013;257:150-4.

18. Janssen PF, Brölmann HA, Huirne JA. Effectiveness of electrothermal bipolar vessel-sealing devices versus other electrothermal and ultrasonic devices for abdominal surgical hemostasis: a systematic review. Surg Endosc. 2012;26:2892-901.

19. Coburn N, Seevaratnam R, Paszat L, et al. Optimal management of gastric cancer: results from an international RAND/UCLA expert panel. Ann Surg. 2014;259:102-8.

20. Baiocchi GL, Tiberio GA, Minicozzi AM, et al. A multicentric Western analysis of prognostic factors in advanced, node-negative gastric cancer patients. Ann Surg. 2010;252:70-3.

21. Heniford BT, Matthews BD, Sing RF, et al. Initial results with an electrothermal bipolar vessel sealer. Surg Endosc. 2001;15:799-801.

22. D'Angelica M, Gonen M, Brennan MF, et al. Patterns of initial recurrence in completely resected gastric adenocarcinoma. Ann Surg. 2004;240:808-16. 